\title{
For-profit hospitals as anchor institutions in the United States: a study of organizational stability
}

Berkeley Franz ${ }^{1 *} \mathbb{D}$, Cory E. Cronin², Vanessa Rodriguez ${ }^{1}$, Kelly Choyke ${ }^{1}$, Janet E. Simon ${ }^{3}$ and Maxwell T. Hall ${ }^{2}$

\begin{abstract}
Background: Anchor institutions, by definition, have a long-term presence within their local communities, but it is uncertain as to whether for-profit hospitals meet this definition; most research on anchor institutions to date has been limited to nonprofit organizations such as hospitals and universities. Accordingly, this study aims to determine whether for-profit hospitals are stable enough to fulfill the role of anchor institutions through a long-term presence in communities which may help to stabilize local economies.

Methods: This longitudinal study analyzes national, secondary data between 2008 and 2017 compiled from the Dartmouth Atlas of Health Care, the American Hospital Association Annual Survey, and County Health Rankings. We use descriptive statistics to calculate the number of closures and mergers of hospitals of different ownership type, as well as staffing levels. Using logistic regression, we also assessed whether for-profit hospitals had higher odds of closing and merging, controlling for both organization and community factors.
\end{abstract}

Results: We found for-profit hospitals to be less stable than their public and nonprofit hospital counterparts, experiencing disproportionately more closures and mergers over time, with a multivariable analysis indicating a statistically significant difference. Furthermore, for-profit hospitals have fewer full-time employees relative to their size than hospitals of other ownership types, as well as lower total payroll expenditures.

Conclusions: Study findings suggest that for-profit hospitals operate more efficiently in terms of expenses, but this also may translate into a lower level of economic contributions to the surrounding community through employment and purchasing initiatives. For-profit hospitals may also not have the stability required to serve as long-standing anchor institutions. Future studies should consider whether for-profit hospitals make other types of community investments to offset these deficits and whether policy changes can be employed to encourage anchor activities from local businesses such as hospitals.

Keywords: Hospital, For-profit, Anchor institution, Closures, Mergers, Population health, Stability, Economics, Communities, Community health

\begin{abstract}
Background
Anchor institutions are large and stable institutions whose actions have an impact on the health, and social and economic strength, of their surrounding communities [1]. Moreover, anchor institutions have the ability to elevate population health by providing jobs and partnering with and investing in local businesses and community
\end{abstract}


initiatives. Typically, scholars describe "meds and eds," or medical and educational organizations, as anchor institutions given their likelihood to be rooted in their communities. This long-term presence, even in the midst of community change, helps to stabilize local economies [1-3]. Given federal requirements for non-profit hospitals to benefit their communities in exchange for tax exemption, most case studies of anchor hospitals have focused on this subset of hospitals and their efforts to elevate population health through targeted employment, purchasing, and health promotion [4]. Because of this limited focus, it's not clear whether for-profit hospitals have similar institutional characteristics which are necessary to fill the role of anchor institution. An approach to engage for-profit hospitals, if successful, might contribute to improved population health and reduce disparities, especially in underserved U.S. communities where these institutions disproportionately operate [5-7].

By definition, anchor institutions have certain features that contribute to their positive impact on communities. These characteristics include longevity in communities and serving as large employers, taxpayers, and purchasers who can stabilize local economies. There is considerable evidence that large institutions, and hospitals in particular, are vital to the communities they inhabit and cause significant economic harm if they close or move from the community. Closures of anchor institutions, like any large employer, impact the local economy through job losses in the hospital itself as well as in related supply chain industries, and through a reduction in consumer service industries, such as stores, restaurants, and banks. The loss of disposable income in the community is especially consequential in communities where opportunities for employment are limited [8].

Existing research suggests that when hospitals close, communities not only lose economic resources, but a consistent supply of health care professionals and services [9]. Hospital closures are more likely to negatively affect the long-term economic prospects of a community when that hospital is the sole hospital in a community, such as in rural areas of the U.S. In these cases, the economic impact can be pronounced- with a lasting decline in per capita income and rise in unemployment [10]. Qualitative studies have documented resident perceptions of these closures, which include anger, resentment, and feelings of abandonment over the need to spend additional time and resources to gain access to health care services following a hospital closure [11].

Existing data suggest that hospital closures are not equally distributed and that certain environments and institutional structures shape these events and their likely impact on communities. For-profit hospitals are more likely to close than their nonprofit hospital counterparts
[12-15]. Hospitals located in states that did not expand Medicaid also are at greater risk of closure, suggesting that hospitals may collapse under the weight of uncompensated care in environments where insurance coverage is lower [16]. Other hospital characteristics, beyond longevity in a community, also impact how much these institutions contribute to communities and may differ between for profit and nonprofit hospitals. For example, the ability of anchor hospitals to provide employment may be somewhat attenuated if hospitals systematically employ staff at different levels, relative to their size. Existing studies do not comment on whether for profit hospitals differ in this regard, but these and other organizational factors may contribute to their potential to function as an economic anchor.

\section{Objective}

As we consider how hospitals of different ownership types may embody the characteristics of an anchor institution, it is critical to examine the stability of an organization and the extent to which that may affect an organization's ability to support a community. Within this context, this study assesses the stability of hospital organizations in two ways: first through an analysis of closures and mergers and second through an assessment of regular staff employed. These factors will provide an understanding of the extent to which for profit hospital organizations have the potential to serve as effective anchor institutions for their communities. In doing so, this study will be the first to utilize over 10 years of data on hospitals in the U.S. to assess the likelihood of closures and mergers and to track long-term employment trends. These findings will provide important insight into whether for-profit hospitals are as likely as other hospitals to serve as anchor institutions in U.S. communities.

\section{Methods}

This longitudinal study was conducted with data from Dartmouth Atlas of Health Care linked with the American Hospital Association (AHA) Annual Survey and County Health Rankings for the years 2008-2017 [17, 18]. These data are ideally suited to the research question because of the comprehensive nature of the hospital data, which include both recent and historical information. The AHA dataset, in particular, is the most complete collection of data on the U.S. hospital population, including for-profit hospitals [19].

In analyzing these data, we utilize a national dataset of general-medical hospitals. While AHA data include all types of hospitals, those that do not fit the description of a general medical hospital were removed for the purposes of this study. We also removed all federal hospitals, considering that their federal support creates different 
expectations of stability and their purposes are often focused on particular populations.

The unit of analysis for the multivariable model is hospital year, with hospitals repeated in the years 2008, 2009, 2010, 2011, 2012, 2013, 2014, 2015, 2016 and 2017. This resulted in a sample of 46,178 hospital years. We merged AHA data with data from County Health Rankings and removed hospital years with missing data via listwise deletion which resulted in our final analytic sample of 44,128 hospital years. The variable that was most commonly the cause of missing data was the poor/fair health rating from County Health Rankings. To draw contrast in hospital staffing trends by ownership type, an additional descriptive analysis was conducted between the years 2008 and 2017, allowing us to consider changes that had occurred between those two points in time.

\section{Study measures}

The multivariable analysis considers two dependent variables: whether the hospital closed during the studied time period and whether the hospital merged with another organization during the studied time period. A merger may include an individual hospital joining a system or changing systems, or a system-level merger for a hospital that was already part of a system.

Independent measures for this study include both hospital characteristics and characteristics of the hospital's county. Hospital measures include ownership (for-profit compared to nonprofit/public); number of beds (50-199, $200-399$, and 400 or more as compared to the reference group of 0-49) and system membership (coded 1 if a hospital system member, 0 if not). County characteristics include the percent of residents reporting poor or fair health; the total number of hospital beds per 1000 county residents; rural classification; and region of the country (Northwest, Midwest, or West, as compared to the South for reference). Hospital staffing variables used in the descriptive analysis for the years 2008 and 2017 include full time equivalents (FTEs) per bed; registerd nurse (RN) FTEs per bed; payroll per bed; and employee benefits per bed.

\section{Statistical analyses}

All analyses were completed in 2020 using STATA 16 [20]. Because of the longitudinal time series nature of this data, we utilized a panel data design specifying a unique ID and year for each hospital, resulting in hospital-years as the unit of analysis. However, for the hospital closures, results showed this methodology not to be appropriate $($ rho $=0.0001)$, and the likelihood test was not significant (chibar2 $(01)=0.001$, prob. $=0.496)$ indicating that the panel-level variance component (years) is unimportant, and the panel estimator is no different than the pooled estimator. Therefore, we ultimately only used this method for the merger analysis. For the panel data analysis, we calculated rho and sigma. Rho indicates the proportion of variance explained by the group level. When rho is zero, the panel-level variance component is unimportant, and the panel estimator is no different from the pooled estimator. Sigma indicates the panel-level standard deviation. Akaike Information Criterion (AIC) and Bayesian Information Criterion (BIC) were calculated for each regression model to assess the model fit.

The descriptive portion of the analysis included frequency, percent, and mean (when appropriate) for each of the study variables. We considered descriptive statistics for the entire sample, as well as for the for-profit subset separately. In the multivariable analysis, we employed logistic regression due to the dichotomous nature of the two dependent variables. The multivariable model considers both organization and county characteristics as control variables.

\section{Results}

Descriptive statistics indicate that $16 \%$ of the hospitalyears in the sample, or 6948 total, represent for-profit ownership. The for-profit subsample of hospitals tends to be characterized by smaller organizations (fewer hospital beds), in areas with more health needs, as measured by the percentage of residents in poor or fair health, and more concentrated in the Southern region. Descriptive statistics also indicate that for-profit hospitals are overrepresented in the number of hospital closures and mergers overall during the studied time period (see Table 1) and across time (Fig. 1).

For-profit hospitals also have fewer full-time positions relative to their size than hospitals of other ownership types, both for total employees (for-profit hospitals 5.39 FTEs per bed compared to 6.56 FTEs per bed of other hospital types in 2017) and for clinical roles (1.82 compared 1.76 for RN specific FTEs per bed). Payroll per bed is also significantly lower $(P<.05)$ for for-profit hospitals, as are employee benefit costs. When looking at both the beginning point and the ending point of our study, gaps between hospital ownership types occur at both points in time, though the gap in RN FTEs does close to some extent in that time period (see Table 2).

The multivariable model predicting hospital closures found a positive significant association for forprofit ownership and communities reporting poorer health (odds ratio $[\mathrm{OR}]=1.06,95 \%$ Confidence Interval $(\mathrm{CI})=1.03-1.10, P<.001) \quad($ Table 3$)$. This indicates that hospitals that are for-profit and communities reporting poorer health had higher odds of closure. The following variables had a significant negative association with hospital closures: hospitals with 200-399 beds (OR $=0.517$, $95 \% \mathrm{CI}=.297-.901, P=.020$ ) or more than 399 beds 
Table 1 Descriptive Statistics of Hospital and County Characteristics, 2008-2017 (N=44,128 hospital-year observations)

\begin{tabular}{|c|c|c|c|c|}
\hline \multirow[b]{2}{*}{ Hospital Characteristics } & \multicolumn{2}{|c|}{ Total Sample } & \multicolumn{2}{|c|}{ For-profit Only } \\
\hline & Frequency & $\%$ & Frequency & $\%$ \\
\hline \multicolumn{5}{|l|}{ Ownership } \\
\hline For-profit & 6948 & 15.75 & 6948 & 100 \\
\hline Nonprofit & 27,060 & 61.32 & & \\
\hline Public & 10,120 & 22.93 & & \\
\hline \multicolumn{5}{|l|}{ Number of Beds } \\
\hline $0-49$ & 12,488 & 28.30 & 1674 & 24.09 \\
\hline 50-199 & 18,460 & 41.83 & 3685 & 53.04 \\
\hline 200-399 & 8911 & 20.19 & 1312 & 18.88 \\
\hline$>400$ & 4269 & 9.67 & 277 & 3.99 \\
\hline Closed & 169 & .38 & 62 & .89 \\
\hline Transit & 517 & 1.17 & 165 & 2.37 \\
\hline System Membership & 26,939 & 61.05 & 5260 & 75.71 \\
\hline Rural & 17,590 & 39.86 & 1810 & 26.05 \\
\hline \multicolumn{5}{|l|}{ Region } \\
\hline Northeast & 5740 & 13.01 & 207 & 2.98 \\
\hline Midwest & 13,193 & 29.90 & 705 & 10.15 \\
\hline West & 8793 & 19.93 & 1518 & 21.85 \\
\hline South & 16,402 & 37.17 & 4518 & 65.03 \\
\hline \multicolumn{5}{|l|}{ Year } \\
\hline 2008 & 4430 & 10.04 & 712 & 10.25 \\
\hline 2009 & 4430 & 10.04 & 712 & 10.25 \\
\hline 2010 & 4430 & 10.04 & 712 & 10.25 \\
\hline 2011 & 4448 & 10.08 & 718 & 10.33 \\
\hline 2012 & 4441 & 10.06 & 706 & 10.16 \\
\hline 2013 & 4445 & 10.07 & 704 & 10.13 \\
\hline 2014 & 4454 & 10.09 & 724 & 10.42 \\
\hline 2015 & 4215 & 9.55 & 654 & 9.41 \\
\hline 2016 & 4429 & 10.04 & 657 & 9.46 \\
\hline 2017 & 4406 & 9.98 & 649 & 9.34 \\
\hline County Characteristics & $\mathrm{N}$ & Mean (SD) & $\mathrm{N}$ & Mean (SD) \\
\hline Percent Reporting Poor/Fair Health & 44,128 & $16.41(4.98)$ & 6948 & $18.29(4.87)$ \\
\hline County Beds / 1000 Population & 44,128 & $5.58(7.06)$ & 6948 & $4.86(5.17)$ \\
\hline
\end{tabular}

$(\mathrm{OR}=0.181, \quad 95 \% \quad \mathrm{CI}=.0551-.596, \quad P=.005), \quad$ system member hospitals $(\mathrm{OR}=0.084,95 \% \mathrm{CI}=.0530-.132$, $P<.001)$, rural location $(\mathrm{OR}=0.442$, 95\% $\mathrm{CI}=.306-$ $.640, \mathrm{P}<.001)$, and the earliest years of the study 2009 $(\mathrm{OR}=0.424,95 \% \mathrm{CI}=.193-.929, P=.032)$ and 2010 $(\mathrm{OR}=0.329,95 \% \mathrm{CI}=.139-.778, P=.011)$. This indicates that hospitals with larger numbers of beds, system member hospitals, and rural location are protective factors for hospital closure.

The likelihood ratio test for the proportion of variance attributable to years was significant rho $=0.83$, chibar2(01) $=1496.51$, prob. $=0.001$. The multivariable model predicting hospital mergers found a positive significant association $(\mathrm{OR}=7.51,95 \% \mathrm{CI}=3.97-14.21$, $P<.001)$ for for-profit ownership controlling for hospital and community-level factors. Communities reporting poorer health, counties with more hospital beds, and the Northeast region also had higher odds of merging (see Table 4). The following variables had a negative association with hospital mergers: hospitals with 200-399 beds or more than 399 beds, system member hospitals, and rural location. This indicates that hospitals with larger numbers of beds, system member hospitals, and rural location may be protective factors for hospital merger. 


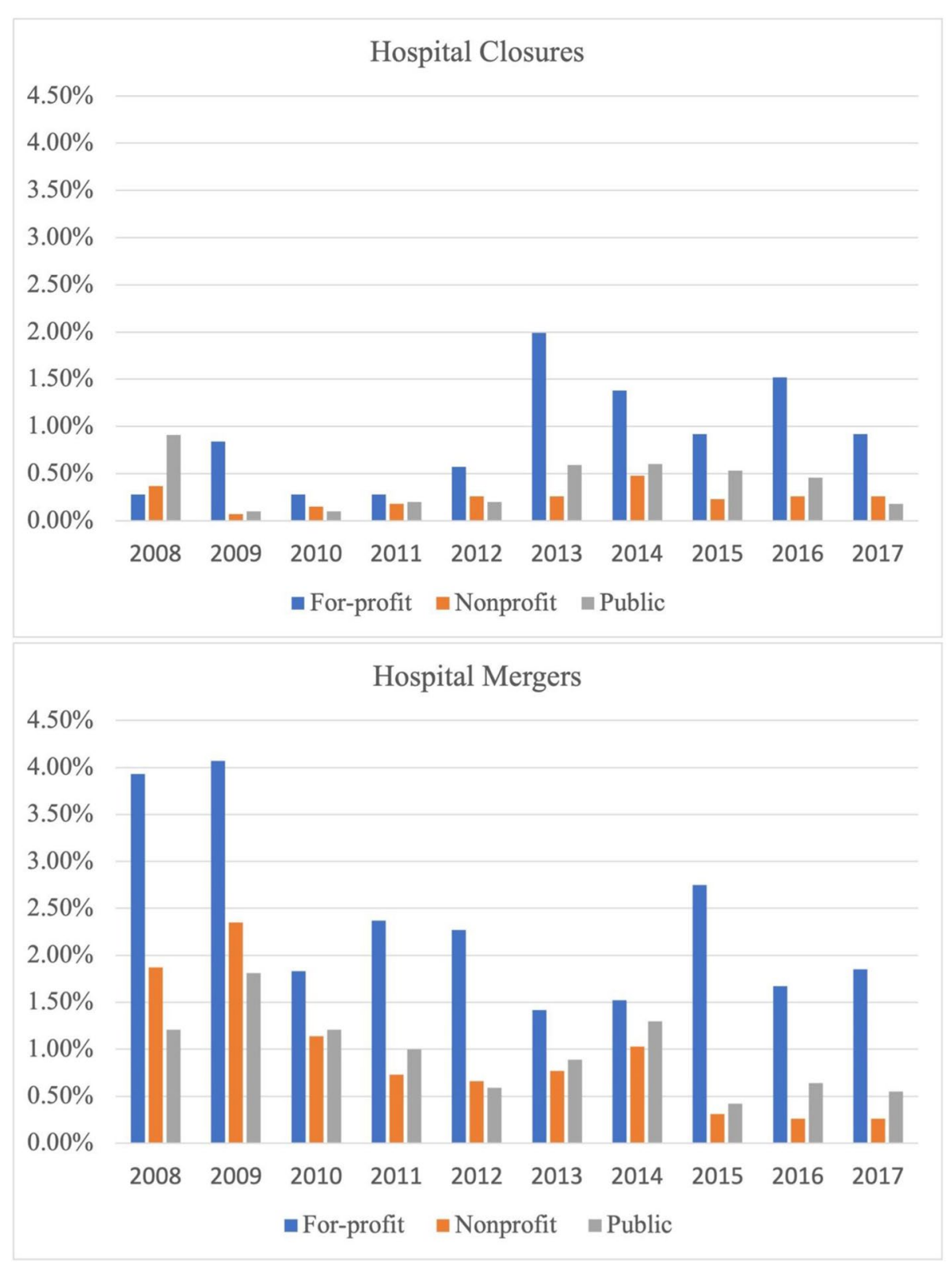

Fig. 1 Percent of Each Hospital Type Experiencing Organizational Change

Table 2 Mean Comparison of Hospital Bed Characteristics by Ownership, 2008 and 2017

\begin{tabular}{|c|c|c|c|c|c|c|c|c|}
\hline & \multicolumn{4}{|c|}{2008} & \multicolumn{4}{|c|}{2017} \\
\hline & \multicolumn{2}{|c|}{ For-profit } & \multicolumn{2}{|c|}{ Other ownership } & \multicolumn{2}{|c|}{ For-profit } & \multicolumn{2}{|c|}{ Other ownership } \\
\hline & $\mathrm{N}$ & Mean & $N$ & Mean & $N$ & Mean & $\mathrm{N}$ & Mean \\
\hline FTE per bed ${ }^{a}$ & 629 & $4.41 *$ & 3541 & 5.79 & 629 & $5.39 *$ & 3712 & 6.56 \\
\hline RNs per bed & 629 & $1.34^{*}$ & 3541 & 1.41 & 629 & 1.82 & 3712 & 1.76 \\
\hline Payroll per bed & 629 & $\$ 220,353^{*}$ & 3541 & $\$ 302,499$ & 629 & $\$ 339,260^{*}$ & 3711 & $\$ 428,565$ \\
\hline Benefits per bed & 629 & $\$ 48,666^{*}$ & 3541 & $\$ 78,471$ & 629 & $\$ 75,187^{*}$ & 3712 & $\$ 113,946$ \\
\hline
\end{tabular}

${ }^{a}$ Boldface indicates statistical significance using two-tailed independent samples T-Test $\left({ }^{*} p<.05\right)$ 
Table 3 Logistic Regression of the Relationship Between Hospital Closures and Hospital/Community Characteristics ( $N=44,128$ hospital-year observations)

\begin{tabular}{|c|c|c|c|}
\hline & \multirow[b]{2}{*}{ OR } & \multicolumn{2}{|l|}{$95 \% \mathrm{Cl}$} \\
\hline & & Low & High \\
\hline Non-profit/Public & Reference & Reference & Reference \\
\hline For-profit $^{\mathrm{a}}$ & $3.187^{* * *}$ & 2.226 & 4.562 \\
\hline Beds $=0-49$ & Reference & Reference & Reference \\
\hline Beds $=50-199$ & 0.947 & 0.671 & 1.336 \\
\hline Beds $=200-399$ & $0.517^{*}$ & 0.297 & 0.901 \\
\hline Beds $>400$ & $0.181 * *$ & 0.055 & 0.596 \\
\hline System Membership & $0.084^{* * *}$ & 0.053 & 0.132 \\
\hline $\begin{array}{l}\text { Percent Reporting Poor/Fair } \\
\text { Health }\end{array}$ & $1.061^{* * *}$ & 1.027 & 1.097 \\
\hline Rural County & $0.442^{* * *}$ & 0.306 & 0.640 \\
\hline County Beds / 1000 Population & 1.020 & 0.999 & 1.042 \\
\hline Region - South & Reference & Reference & Reference \\
\hline Region - Northeast & 1.304 & 0.759 & 2.240 \\
\hline Region - Midwest & 0.676 & 0.416 & 1.098 \\
\hline Region - West & 0.653 & 0.414 & 1.029 \\
\hline Year - 2008 & Reference & Reference & Reference \\
\hline Year - 2009 & $0.424^{*}$ & 0.193 & 0.929 \\
\hline Year - 2010 & $0.329 *$ & 0.139 & 0.778 \\
\hline Year - 2011 & 0.489 & 0.218 & 1.098 \\
\hline Year - 2012 & 0.717 & 0.348 & 1.476 \\
\hline Year - 2013 & 1.525 & 0.832 & 2.798 \\
\hline Year - 2014 & 1.572 & 0.864 & 2.860 \\
\hline Year - 2015 & 1.143 & 0.582 & 2.243 \\
\hline Year - 2016 & 1.458 & 0.772 & 2.752 \\
\hline Year - 2017 & 1.002 & 0.499 & 2.011 \\
\hline AIC & 1936.299 & & \\
\hline BIC & 2118.89 & & \\
\hline
\end{tabular}

${ }^{a}$ Boldface indicates statistical significance $\left({ }^{* * *} p<.001 ;{ }^{* *} p<.01 ;{ }^{*} p<.05\right)$

\section{Discussion}

City planners and policy experts are increasingly looking to for-profit businesses to serve as community-engaged institutions who stabilize the economic base of U.S. communities and bolster health and well-being [21, 22]. For-profit hospitals may be one example of businesses being successfully leveraged to improve local communities, but the current study findings suggest that one challenge to the prospect of for-profit hospitals serving as anchor institutions may be their stability and longevity in the communities they serve. For-profits are more likely than their counterparts to close or to merge, which indicates that, as an organizational type, they are less reliable to provide economic support over time to a community. Closures are a clear example of a way in which an organization may exit a community, taking with it a substantial number of jobs and other means of injecting
Table 4 Logistic Regression of the Relationship Between Hospital Mergers and Hospital/Community Characteristics ( $N=44,128$ hospital-year observations)

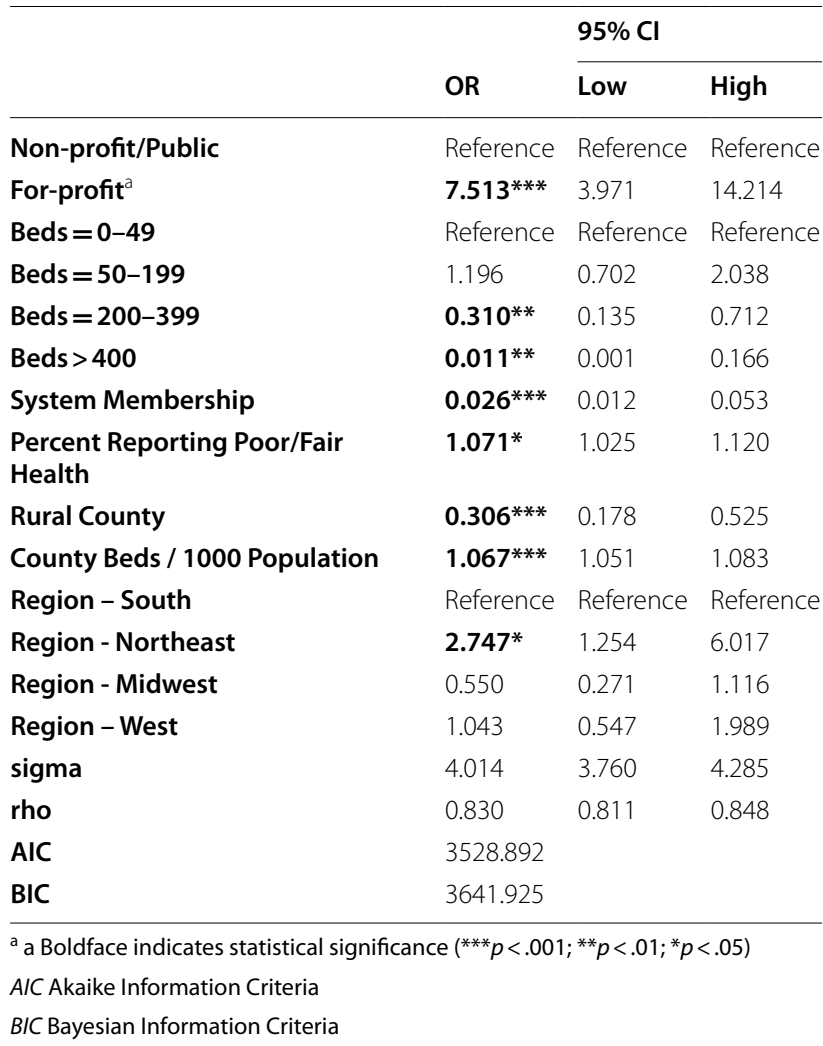

money into a local economy. Beyond closures, this is important to consider in the case of mergers as well, since a merging hospital may find itself with a different identity or mission, potentially weakening its established community ties, or even with a reduced workforce. At the same time, for-profit hospitals tend to exist in areas with greater health needs [23]. These areas also face greater numbers of hospital closures and mergers overall, as our findings show. This combination of factors indicates that for-profit hospitals hold critical potential for strengthening local economies but may be limited by organizational characteristics that make them less stable in communities where there is also greater need.

It is perhaps unsurprising that for-profit hospitals, which by their nature have the purpose of generating revenue for shareholders, are more inclined to pursue business strategies such as closures or mergers when operation in a community no longer becomes financially advantageous. Yet, such strategies may be in conflict with a mission of serving a community's well-being, forcing for-profit hospitals to reconcile their business decisions as a for-profit organization with the purpose they serve as a hospital. This may be further complicated by a 
decentralized decision-making structure that is common with for-profit hospitals that exist as part of a system; in such systems, headquarters that exist elsewhere and the executives who work there may not be plugged into the needs of a local community, making the consequences of an organization's business strategies less apparent.

Departures of hospitals from rural communities have the potential to hit particularly hard in this way. One finding of our analysis portrays hospitals to be more stable in rural communities, which appears to counter recent literature on the topic. Considering this, we completed a post-hoc analysis to consider rural closure trends, which provide a clearer narrative [9]. While rural closures were less likely to occur when looking at the studied time period as a whole due to fewer occurrences as compared to non-rural communities in the early years of the study, we can see a clear trend in rural hospital closures increasing over time. For example, in $2010, .1 \%$ of rural hospitals closed, compared to .2\% of nonrural; in $2016, .8 \%$ of rural hospitals closed, compared to .3\% of nonrural (see Fig. 1). This is a phenomenon worth continued examination and study, particularly given the challenges it presents for rural communities both in regard to health and economic well-being.

Beyond institutional stability, another defining characteristic of anchor institutions is their propensity to employ large numbers of people [2, 24]. Again, study findings indicate that this is an area where a for-profit organization's business strategies may result in less economic benefit for the community. Likely due to their emphasis on fiscal efficiency, for-profit hospitals employ fewer people than nonprofit hospitals of a comparable size. It is interesting that the employment numbers are more similar for clinical roles, which may point to accreditation or licensure standards that are applicable to all hospitals across ownership status or quality of care standards all hospitals would consider [25-27]. On the other hand, all types of hospitals may be facing consequences of a national nursing shortage and therefore find themselves unable to staff beyond certain levels [28].

Despite less stability and lower employment levels, forprofit businesses, including hospitals contribute to the local tax base which may support the economic health of their communities in ways not shared by private nonprofit and public institutions. In both urban and rural communities where major institutions have left, forprofit hospitals may contribute to a shrinking tax base and provide critical support for community health and well-being. It is not clear, however, if these contributions are enough to offset other characteristics, such as the propensity to close, when weighing their economic contributions to U.S. communities. For-profit hospitals, like other businesses, may also make other contributions to their communities which are not measured in this study, including through health promotion and community development partnerships. This may include wellness programs among employees or extend to the community at large [29]. Indeed, the emphasis on social in addition to fiscal responsibility, is evident among some for-profit businesses and there may be potential to leverage such investments to improve the health of communities [21, 30]. Because of their size and influence, for-profit organizations, including hospitals, should not be discounted as potential anchor institutions, but more studies are needed to understand the extent and scope of their contributions in U.S. communities.

A recognition that for-profit hospitals have the potential to serve as anchor institutions should not be confused with an assumption that all for-profit hospitals have the desire or even willingness to take on this role and the greater community responsibility it may represent. Future studies are necessary to understand how for-profit hospitals define their role in population health improvement, including through traditional anchor activities like employment and procurement or through direct investments and community partnerships. Recent changes in reimbursement may encourage moving toward value from traditional fee-for-service models [31, 32], but whether these changes are influential in regard to anchor activities is still unknown. Policymakers should consider the potential role that for-profit hospitals may play in population health initiatives and what policies may activate investments in this area in the absence of formal community benefit responsibilities.

\section{Limitations}

There are several limitations that must be weighed against the novel contributions of this study. The first is that the data are self-reported; there is the possibility that hospitals completing the annual AHA survey interpret questions differently. It is also important to note that closures are a rare event, which means that we are assessing variation among a very small sample of hospitals. Due to our reliance on secondary, quantitative data, we also have limited context to understand why organizational characteristics differ by hospital type. We are also unable to evaluate outcomes of these events. It is possible that a merger may provide added resources to a community, or that a closure of a hospital does not mean a departure entirely of a health care organization's presence in a neighborhood (e.g., a hospital ceased providing inpatient services, but remains as an outpatient care provider). In both of these scenarios, mixed methods or qualitative research studies would provide more insight into the impact of these changes on the well-being of community residents. These methods would also allow for a more 
nuanced understanding of organizational decision-making and the link between ownership type and key hospital characteristics.

\section{Conclusion}

For profit hospitals are not often considered as anchors, despite serving as key institutions in their communities. For profit hospitals, unlike their nonprofit counterparts, contribute to the local tax base and may stabilize their communities in ways that researchers have not fully appreciated. Still, for profit hospitals have characteristics that set them apart from other hospitals and which may limit their ability to provide long term support for community health and economic stability. Recognizing the potential contributions of these institutions is critical to understanding what communities stand to gain and lose when hospitals participate in population health improvement. These data will help policymakers leverage support for expanded incentives for explicitly adopting an anchor framework for population health improvement.

\section{Abbreviations}

AIC: Akaike's Information Criterion; AHA: American Hospital Association; BIC: Bayesian Information Criterion; Cl: Confidence Interval; FTE: Full Time Equivalent; OR: Odds Ratio; RN: Registered Nurse.

\section{Acknowledgements}

Not applicable.

\section{Authors' contributions}

$\mathrm{BF}$ generated the concept and design of the study and interpreted data. CC generated the concept and design of the study; acquired, analyzed, and interpreted data. VR acquired data. KC interpreted data. JS analyzed data. MH acquired data. All authors drafted the manuscript or contributed to revisions. All approve the final manuscript and agree to be accountable for all aspects of the work.

\section{Funding}

This work is supported by a grant from the Robert Wood Johnson Foundation's Understanding and Supporting Anchor Business program, managed by Academy Health (Grant No: 76912). Summer research support for an undergraduate student to participate in the project was provided by the Ohio University Research Apprenticeship Program. Funding bodies had no role in the design and conduct of the study; collection, management, analysis, and interpretation of the data; preparation, review, or approval of the manuscript: and decision to submit the manuscript for publication.

\section{Availability of data and materials}

The County Health Rankings data analyzed during the current study are publicly available at https://www.countyhealthrankings.org/. The Dartmouth Atlas of Health Care data analyzed during the current study are publicly available at https://www.dartmouthatlas.org/. Additional data analyzed during the current study are available from the American Hospital Association Annual Survey but restrictions apply to the availability of these data, which were used under license, and so are not publicly available. Data are however from the authors upon reasonable request and with the permission of the American Hospital Association.

\section{Declarations}

Ethics approval and consent to participate

No administrative permissions beyond purchasing were required to access and use American Hospital Association data in this study.
Consent for publication

Not applicable.

\section{Competing interests}

The authors declare that they have no competing interests.

\section{Author details}

${ }^{1}$ Department of Social Medicine, Heritage College of Osteopathic Medicine, Ohio University, Irvine Hall 210, Athens, OH 45701, USA. ${ }^{2}$ Department of Social and Public Health, Ohio University, Grover Center W359, Athens, OH 45701 , USA. ${ }^{3}$ College of Applied Health Sciences and Wellness, Ohio Unitversity, Ohio Musculoskeletal and Neurological Design, Grover Center E150, Athens, OH 45701, USA.

Received: 29 April 2021 Accepted: 16 November 2021

Published online: 11 December 2021

\section{References}

1. Harris M, Holley K. Universities as anchor institutions: economic and social potential for urban development. In: Paulsen MB, ed. Higher Education: Handbook of Theory and Research. Springer International Publishing; 2016. p. 393-439. https://doi.org/10.1007/978-3-319-26829-3 8.

2. Zuckerman D, Sparks H, Dubb S, Howard T. Hospitals building healthier communities: Embracing the anchor mission. College Park, MD: The Democracy Collaborative at the University of Maryland. Published online 2013:1-2.

3. Hutchison R, Cairns B. Community anchor organizations: Sustainability and independence. Hybrid Organizations and the Third Sector. Published online 2010:134-152. doi:https://doi.org/10.1007/978-0-230-36439-4_7.

4. Sherman SA, Doussard M. Which hospitals participate in community building? What medical anchors spend on community economic development. J Urban Aff. 2019;41(7):999-1016. https://doi.org/10.1080/07352 166.2018 .1559649$.

5. Potter SJ. A Longitudinal Analysis of the Distinction between ForProfit and Not-for-Profit Hospitals in America. J Health Soc Behav. 03/2001;42(1):17. doi:https://doi.org/10.2307/3090225

6. Parrillo AJ, de Socio M. Universities and hospitals as agents of economic stability and growth in small cities: A comparative analysis. Published online 2014. doi:https://doi.org/10.13016/M2BX1F

7. Harkavy I, Zuckerman H. Eds and meds: Cities' hidden assets Accessed January 30, 2021. http://community-wealth.org/sites/clone.communitywealth.org/files/downloads/report-harkavy.pdf

8. Lendel I, Piazza M, Ellerbrock M. Lordstown GM Plant closure economic impact study. Published online 2019. https://engagedscholarship.csuoh io.edu/cgi/viewcontent.cgi?article=2594\&context=urban_facpub

9. Germack HD, Kandrack R, Martsolf GR. When rural hospitals close, The Physician Workforce Goes. Health Aff . 2019;38(12):2086-2094. doi:https:// doi.org/10.1377/hlthaff.2019.00916.

10. Holmes GM, Slifkin RT, Randolph RK, Poley S. The Effect of Rural Hospital Closures on Community Economic Health. Health Serv Res. 04/2006;41(2):467-485. doi:https://doi.org/10.1111/j.1475-6773.2005. 00497.x

11. Countouris $\mathrm{M}$, Gilmore $\mathrm{S}$, Yonas $\mathrm{M}$. Exploring the impact of a community hospital closure on older adults: a focus group study. Health Place. 2014:26:143-8. https://doi.org/10.1016/..healthplace.2013.11.008.

12. Puro N, Borkowski N, Feyereisen S, et al. The role of organizational slack in buffering financially distressed hospitals from market exits. J Healthc Manag. 2021;66(1):48-61. https://doi.org/10.1097/JHM-D-20-00004.

13. Cronin C. Community benefit practices and their relationships to organizational performance and survival. Acad Manag Proc. 2016;2016(1):10853. https://doi.org/10.5465/ambpp.2016.10853abstract.

14. Horwitz JR. Do different types of hospitals act differently? Accessed 30 Jan, 2021. https://repository.law.umich.edu/cgi/viewcontent.cgi?article= $1044 \&$ context=other

15. U.S. Government Accountability Office. Rural Hospital Closures: Number and Characteristics of Affected Hospitals and Contributing Factors. 2018;(GAO-18-634). Accessed January 29, 2021. https://www.gao.gov// assets/700/694125.pdf 
16. Lindrooth RC, Perraillon MC, Hardy RY, Tung GJ. Understanding the relationship between Medicaid expansions and hospital closures. Health Aff. 2018;37(1):111-20. https://doi.org/10.1377/hlthaff.2017.0976.

17. How Healthy is your County? Accessed January 29, 2021. https://www. countyhealthrankings.org/

18. Dartmouth Medical School., Center for the Evaluative Clinical Sciences. The Dartmouth atlas of health care. Published online 1996

19. Association AH. Others. AHA annual survey database. Washington, DC: American Hospital Association. Published online; 2005.

20. StataCorp LLC. Stata Statistical Software. Release 16.[software]. College Station, TX. Published online 2019.

21. Scott MM, Baylor D, Spaulding S. What if cities challenged local businesses to reinvent social responsibility? Accessed 14 Sept 2021. https:// www.urban.org/sites/default/files/publication/81101/2000803-what-ifcities-challenged-local-businesses-to-reinvent-social-responsibility_0.pdf

22. Bhattacharya CB, Sen S, Korschun D. Leveraging Corporate Responsibility: The Stakeholder Route to Maximizing Business and Social Value. Cambridge University Press; 2011. https://play.google.com/store/books/ details?id=2vMhAwAAQBAJ

23. Cronin CE, Franz B, Choyke K, Rodriguez V, Gran BK. For-profit hospitals have a unique opportunity to serve as anchor institutions in the US. Published online. 2020.

24. Vize R. Hospitals as anchor institutions: how the NHS can act beyond healthcare to support communities. BMJ. 2018;361. https://doi.org/10. 1136/bmj.k2101.

25. Needleman J, Buerhaus P, Mattke S, Stewart M, Zelevinsky K. Nursestaffing levels and the quality of care in hospitals. N Engl J Med. 2002;346(22):1715-22. https://doi.org/10.1056/NEJMsa012247.

26. Oppel E-M, Young GJ. Nurse staffing patterns and patient experience of care: an empirical analysis of U.s. hospitals. Health Serv Res. 2018:53(3):1799-818. https://doi.org/10.1111/1475-6773.12756.

27. Olley R, Edwards I, Avery M, Cooper H. Systematic review of the evidence related to mandated nurse staffing ratios in acute hospitals. Aust Health Rev. 2019;43(3):288-93. https://doi.org/10.1071/AH16252.

28. Winter V, Schreyögg J, Thiel A. Hospital staff shortages: environmental and organizational determinants and implications for patient satisfaction. Health Policy. 2020;124(4):380-8. https://doi.org/10.1016/j.healthpol. 2020.01.001.

29. Anchor Businesses Can Be Change Makers For Community Health Improvement. Accessed September 13, 2021. https://www.healthaffairs. org/do/10.1377/hblog20200427.314980/full/

30. Pioneering W. Upstream all the way. Accessed 14 Sept 2021. https://cente rforcommunityinvestment.org/sites/default/files/2019-07/CCl-\%20Hos pital\%20Motivations\%20Paper.pdf

31. Garg A, Homer CJ, Dworkin PH. Addressing Social Determinants of Health: Challenges and Opportunities in a Value-Based Model. Pediatrics. 2019;143(4). doi:https://doi.org/10.1542/peds.2018-2355

32. Peltz A, Rogers S, Garg A. An Equity Lens for Identifying and Addressing Social Needs Within Pediatric Value-Based Care. Pediatrics. 2020;146(4). doi:https://doi.org/10.1542/peds.2020-0320

\section{Publisher's Note}

Springer Nature remains neutral with regard to jurisdictional claims in published maps and institutional affiliations.

Ready to submit your research? Choose BMC and benefit from:

- fast, convenient online submission

- thorough peer review by experienced researchers in your field

- rapid publication on acceptance

- support for research data, including large and complex data types

- gold Open Access which fosters wider collaboration and increased citations

- maximum visibility for your research: over $100 \mathrm{M}$ website views per year

At BMC, research is always in progress.

Learn more biomedcentral.com/submissions 